\title{
ESCRAVIDÃO POR DÍVIDA E AS RAÍZES DO TRABALHO ESCRAVO NA ESFERA RURAL: UMA ANÁLISE À LUZ DAS LACUNAS DE CRITICIDADE NO DIREITO AGRÁRIO BRASILEIRO
}

\section{BONDED LABOUR AND ITS ROOTS IN RURAL SPHERE. AN ANALYSIS BY CRITICALITY GAPS IN THE BRAZILIAN AGRICULTURAL LAW}

\author{
${ }^{1}$ Ana Carolina Amaral de Pontes
}

\section{RESUMO}

As relações entre o Direito Agrário e o fenômeno do trabalho escravo derivam de situações de opressão no trabalho rural por vezes invisibilizadas pelo debate acadêmico agrário. Faz-se necessário analisar a identidade brasileira do latifúndio para uma abordagem interconectada do enfrentamento da escravidão por dívida. Sair da bolha legalista para reconhecer sua relação com a gênese e a manutenção do trabalho escravo é nosso foco. Outras legislações, tampouco a CF 1988 foram capazes de exterminar a escravidão, "atualizada" em moldes contemporâneos. O trabalhar acrítico dos institutos agrários provocam falsa assepsia de realidades do contexto brasileiro, que abordamos aqui.

Palavras-chave: Escravidão por dívida, Direito agrário, Latifúndio

\begin{abstract}
Relations between the Agrarian Law and slave labor phenomenon derived from situations of oppression in rural work sometimes are invisibilized by the agrarian academic debate. It is necessary to analyze the Brazilian identity of land property for an interconnected approach to the bonded labour. The exit from legalistic bubble to recognize its relation to the genesis and maintenance of slave labor is our focus. Other regulations, either the CF in 1988 cannot able to eradicate slavery, "updated" in contemporary mold. The uncritical view of agrarian institutes cause false aseptic realities of the Brazilian context, is our approach.
\end{abstract}

Keywords: Bonded labour, Agrary law, Land property

\footnotetext{
${ }^{1}$ Doutora em Educação pela Universidade Federal de Pernambuco - UFPE, Pernambuco (Brasil). Professora da Universidade Federal Rural de Pernambuco - UFPE, Pernambuco (Brasil). E-mail: professoraanapontes@gmail.com
} 


\section{NOTAS INTRODUTÓRIAS}

Não é possível dissociar a história da colonização territorial brasileira da história da formação do trabalho rural no Brasil. A primeira tem em sua marca a noção preliminar de que os concessionários das parcelas territoriais da Colônia previam a utilização de mão de obra, quase que exclusivamente escrava, para explorar as terras concedidas através das capitanias e estas por sesmarias. Nesse sentido, a escravidão e a concessão baseada em critérios predominantemente de classe e sobrenomes compreendem dois aspectos que marcaram de tal forma a constituição do trabalho rural no Brasil que mantém suas cicatrizes entreabertas até os dias contemporâneos.

Ainda que encerradas formalmente em 1822 (poucos dias antes da proclamação da independência política do Brasil) os efeitos práticos das capitanias hereditárias ainda se fizeram visíveis e sobretudo seus efeitos políticos e culturais permaneceram ainda por mais tempo. Por outro lado, a escravatura, embora tenha encontrado seu termo aparente em 1888 não por acaso também em curto espaço de tempo antes da proclamação da República - não deixou de imprimir suas vergastadas nas formações residenciais de diversas cidades, fossem nos centros urbanos, fossem na zona rural, bem como determinou de forma profunda o tom das negociações da nova classe de ex-escravos e escravas em uma relação extremamente desigual.

Sem pretensões de usurpar a narrativa histórica a especialistas, usamos destes dois breves marcos para lançar as âncoras temporais de nossa análise que tem como objetivo principal estabelecer uma contribuição crítica na percepção que existem lacunas na abordagem das relações entre estudos conhecidos em Direito Agrário (especialmente doutrinas gerais) e o fenômeno do trabalho escravo por dívidas na esfera rural. Como acessórios, discorrer sobre características próprias do trabalho escravo na esfera rural observando peculiaridades, bem como também trazer uma provocação sobre a relação com a questão da proliferação do latifúndio no Brasil. Esta lacuna é identificada como nosso problema, cuja reflexão ora apresentada busca contribuir e provocar outras visões dentro do Direito Agrário. A escolha pela linha proposta, identificada em "Atividades agrárias como objeto do Direito Agrário" foi propositalmente pensada pela percepção que vem ocorrendo frequentemente um deslocamento de objeto, como se a visão de trabalho rural existisse apenas na identificação de pertencimento na esfera do Direito do Trabalho, inclusive nas situações de desvirtuamento para a escravidão contemporânea, quando é sobejamente conhecido que a 
escravidão por dívidas tem características acentuadas na esfera agrária por diversos fatores que demonstraremos no presente artigo. A visão, simplista, não apenas enfraquece a gama de temáticas concernentes ao Direito Agrário, mas contribui indiretamente para invisibilizar diversas situações de opressão provenientes do trabalho rural que poderiam ser trabalhadas em debates acadêmicos da área jurídica agrária, o que justifica a relevância da contribuição, da abordagem e da escolha da linha. Compreende-se necessário o fomento da temática por pesquisadores e pesquisadoras que busquem ir além, realizando a indispensável interdisciplinaridade para obtenção de recursos que instruam a luta por aumentar o leque de temáticas da realidade agrária, e que estas, numa perspectiva mais global, possa contemplar a dignidade e os direitos humanos.

\section{A FALSA DICOTOMIA DA IMPERTINÊNCIA DO APROFUNDAMENTO DA TEMÁTICA DO TRABALHO RURAL DENTRO DO ESTUDO DO DIREITO AGRÁRIO}

Sob certo ponto de vista, as discussões sobre a pertinência ou não das relações de trabalho no estudo do Direito Agrário, ainda se mostram surpreendentes. Nesse sentido, LARANJEIRA (1984), SANTOS (1993) e MARQUES (2009) apresentam visões a respeito da questão. O primeiro, ainda que reconheça a influência de uma questão sobre outra, pondera pela divisão de áreas, assegurando o pertencimento do Direito do Trabalho como disciplinador. Santos e Marques reforçam por sua vez o conceito de interdependência, ainda que de forma frágil, e reforçando uma divisão que - a nosso ver - parece deslocar o cerne da questão para uma dicotomia no fundo inexistente: de que "as diferenças no contexto normativo são evidentes" (MARQUES, 2009, p. 190). Reforça Santos em citação ratificada e escolhida por Marques que:

$\mathrm{O}$ que não se pode negar é a interdependência, quando o trabalhador depende do produtor rural como empregador e este depende daquele para desenvolver sua atividade. Não se pode confundir o âmbito da regulação jurídica. O produtor rural, muitas vezes, no exercício de sua atividade, participa de atos jurídicos não regulados no Direito Agrário, como a compra de um trator, o contrato de transporte rodoviário de seus produtos, a locação de um armazém, etc. Da mesma forma, ao contratar empregados, estará se sujeitando a um outro ramo do direito que não é agrário. (MARQUES, 2009, p. 191).

Ora, neste sentido, restringir o debate à questão normativa, onde é evidente a competência da esfera trabalhista, seria minimizar excessivamente a questão. Lembremos, à tempo inclusive, que o breve debate sobre a competência da Justiça trabalhista, por exemplo, para julgar danos morais cometidos durante a relação de trabalho foi naturalmente encampada 
para o decisório trabalhista, justamente pela percepção de que a interdependência se fazia explícita. Entretanto, não é essa questão periférica que jogamos luz no debate, e sim uma visão mais ampla. Sigamos.

A perceptível fragilidade do estudo do Direito Agrário em relação à atualidade de suas discussões é palpável, ainda que se custe a admissão. Com frequência, a atualização das obras mais consultadas ou popularizadas ocorre com menor frequência que outras áreas, como Direito Ambiental, por exemplo, e não é incomum reedições realizadas com poucos acréscimos e menos críticos do que o desejado. Lamentavelmente as raízes, já sugeridas no início deste artigo, podem ter sido lançadas na constituição dos debates do Direito na perspectiva agrária, em especial no enredamento da visão privilegiada dos bens sobre as relações humanas no campo. Tanto quando a lenta transição do Código Civil de 1912 para o atual, que realizou a mudança da prioridade das coisas para o foco sobre as pessoas e suas relações, o Direito Agrário também vem demonstrando com a contribuição de novos e novas juristas até sob perspectivas menos datadas ${ }^{1}$. Ainda há um movimento lento e persistente que busca afastar a predominância dos estudos focados em Direitos Reais como relação prioritária do Direito Agrário. Noções mais condizentes com a contemporaneidade dão conta da necessidade premente de um Direito Agrário de compleição constitucional e estabelecendo as indispensáveis relações com o Direito Ambiental, numa percepção das relações entre as pessoas e o ambiente numa visão de desenvolvimento com sustentabilidade. A admissão da ligação humana neste contexto, demonstra que os bens compreendem um instrumento e não um protagonismo.

Ora, uma vez que ainda lutamos por uma visão mais ampla do Direito Agrário não nos surpreende que ainda existam discussões sobre compartimentalizações de assuntos que terceirizam relações que de fato constituem um foco relevante do Direito Agrário. E que não podem perder de vista as relações humanas na construção da produção agrária. A crítica, porém, é que a "demissão" de certos temas resulta num "açúcar amargo" para utilizar uma expressão gullariana ${ }^{2}$. Isto porque é indiscutível que o necessário debate sobre a escravidão na esfera do trabalho rural tem peculiaridades absolutamente próprias em comparação ao

\footnotetext{
${ }^{1}$ Aqui recordamos, por exemplo, as contribuições de Elisabete Maniglia, com a obra disponibilizada "As interfaces do Direito Agrário e dos Direitos Humanos e a Segurança Alimentar" pela Google Books. Aliás da autora é a tese de doutorado "O Trabalho Rural sobre a ótica do Direito Agrário: uma opção ao desemprego no Brasil", defendida em 2000 na UNESP.

${ }^{2}$ Ferreira Gullar retrata através de jogos de palavras, em $\mathbf{O}$ açúcar, analisa as más condições de trabalhadores rurais e suas relações com o lucro: "Em usinas escuras. Homens de vida amarga. E dura. Produziram este açúcar. Branco e Puro" (GULLAR, 2004, p.165). Refletindo sobre a falsa doçura do preço de produto típico da identidade brasileira, aponta a quem realmente pertence.
} 
trabalho escravo urbano (e aqui não discutimos apenas a noção de espaço rural como esfera geográfica, ainda que aceitemos que estas recrudescem os conflitos em função da ausência do Estado nos rincões do país, onde outros poderes vem se estabelecendo à força de atividades madeireiras, mineração, carvoarias entre outras). Tais peculiaridades podem ser adequadamente fomentadas e debatidas através de estudos agrários, calcando-se em reflexões anteriores que oferecem bases que nos sinalizem as questões próprias da realidade agrária brasileira. Esta noção aqui compartilhada, porém, parte do princípio da- por falta de melhor termo- "percepção da habilitação intelectual para o debate" de estudiosos e estudiosas do Direito Agrário. E apresenta, ao mesmo tempo, também a questão dos efeitos: é extremamente danoso relegar o debate sobre o trabalho rural à exclusividade do Direito do Trabalho em função inclusive dos frutos possíveis e da produção intelectual da área agrária. Que se beneficia da constatação da relevância da temática dentro do Direito do Agrário, favorecendo a ampliação de obras mais completas que contemplem o debate do trabalho escravo rural e que atinjam o objetivo da consolidação de um Direito Agrário numa perspectiva constitucional e sustentável.

\section{O LUGAR DO TRABALHO ESCRAVO EM CONFLUENCIA COM OS OBJETIVOS DE CRESCIMENTO DA DISTRIBUIÇÃO DE TERRAS E A VISÃO DE EXPLORAÇÃO PARA PRODUÇÃO AGRÍCOLA BRASILEIRA AO LONGO DO TEMPO.}

O Brasil notabilizou-se, como é historicamente conhecido, pela postura inicial de escravizamento indígena. Tal situação foi decorrente de alguns fatores preponderantes, como a exploração inicial de pau-brasil e posteriormente da cana de açúcar (os metais ainda não haviam sido descobertos, só solidificando-se sua pesquisa e extração na interiorização da colonização). A escravidão indígena durou cerca de cem anos, sendo minada pelas revoltas indígenas (mais fortalecidas que na escravidão negra em função do conhecimento do conhecimento geográfico) e pressão jesuítica. Em 1549 a vinda de escravos e escravas de forma esporádica, como "parte da bagagem" de portugueses e portuguesas é reforçada através de um decreto na regência de D. Catarina para que senhores de engenho importassem até cento e vinte escravos por ano (GONZALES e ANDRADE, 2007, p. 58).

Quando o açúcar brasileiro toma a dianteira da produção mundial, porém, a escravidão é largamente utilizada no Brasil, dando ao mesmo o feitio histórico conhecido. O período de fortalecimento açucareiro trouxe cerca de quinhentas mil pessoas escravizadas para o Brasil, reforçando-se no período mineratório com mais de um milhão e setecentas pessoas, conforme também demonstram GONZALES e ANDRADE (2007). Mesmo após a 
suposta extinção do tráfico no Brasil em 1831, ele perdura até 1850, tendo estimado neste período proibido da entrada de cerca de quinhentas mil em condições de escravizamento humano.

Paralelamente, o Brasil viveu o sistema de capitanias hereditárias que constituíam-se em faixas de terra tomando por mediatriz a linha imaginária de Tordesilhas, ainda hoje bastante discutida quanto ao seu aspecto geográfico ${ }^{3}$. Os chamados donatários deveriam povoar estas faixas, explorá-las às suas expensas e governá-las distribuindo as conhecidas sesmarias e tendo direito de escravizamento de indígenas, sempre em nome da Coroa Portuguesa. Desde este ponto, portanto, observamos a ligação primária entre a propriedade sobre a terra acompanhada pela percepção de propriedade sobre os habitantes da terra. Essa governabilidade incluía a formação inicial de governadores e juízes, que posteriormente começarão a ser enviados por Portugal diante dos percalços de governabilidade encontrados.

É interessante notar que a figura do sesmeiro, que seriam indicados pelos donatários, e que desempenham, na prática a função direta de administração dos lotes de terra no ponto de vista exploratório, este tinha o direito de posse, mas não de domínio. Caso não houvesse produção adequada em dois anos (ainda que houvesse possibilidades de justificativas), seria possível a retomada da terra. Cumpre observar que as sesmarias não poderiam ser conferidas aos chamados hereges, que incluiriam pessoas de origem árabe, judaica, indígenas e pessoas negras. É importante ressaltar que este instrumento de retomada por improdutividade da terra foi claramente passando à "letra morta", como bem recordam GONZALES e ANDRADE (2007, p 58). As raras retomadas cujas documentações venceram o tempo apontam evidências sobretudo de disputas políticas que passam muito distante de questões produtivas. Outra violação frequente constituíam as determinações de tamanho trazidas pela Coroa. Nota-se que em 1822, época da suspensão da distribuição não havia terras a serem mais distribuídas, ainda que houvesse latifúndios com mais de cem quilômetros de extensão.

É interessante notar que no período de 1850, com a chamada Lei de Terras, foi organizada uma estratégia de limitação de poder da população de pequenos posseiros e posseiras, pessoas libertadas recentemente da condição de escravas e imigrantes: apesar da pressão para o fim da escravidão, focando-se o contingente populacional de futuros consumidores e consumidoras, mas evitando-se que estes e estas alterem sua condição adquirindo legalmente terras brasileiras. Dessa forma, constituíam-se uma boa massa de mão

\footnotetext{
${ }^{3}$ Discute-se o formato comumente estudado nas escolas e a efetiva divisão neste aspecto. Sugere-se a publicação da Revista de História por Aline Melo "Uma questão de limites", disponível em <http://www.revistadehistoria.com.br/secao/em-dia/uma-questao-de-limites-1>. Acesso em março de 2016.
} 
de obra assalariada, mas sem rivalizar a possibilidade de ascensão social pela aquisição de terras. Observa José Murilo de carvalho que a Lei de terras constituiu o casamento do capital com a propriedade da terra (CARVALHO, 1980, p. 78).

Localiza-se, contudo, a existência das chamadas "brechas camponesas", que constituíam uma economia paralela alimentar complementar a monoculturas como a de açúcar no Nordeste brasileiro, baseando-se na produção de alimentos em terras cedidas às margens das plantações de cana, abastecendo mercados locais além das próprias famílias como explica CARDOSO (1987, p.97-120). Com as terras cedidas apenas provisoriamente a tendência histórica na segunda metade do século XX foi a privação deste acesso limitado à terra, com a expulsão destas famílias camponesas. Essa luta de foreiros e foreiras vem a ser evidenciada nas primeiras lutas camponesas.

Estabelecendo uma ordem temporal verificamos que o estabelecimento das primeiras regras de proteção do trabalhador ou trabalhadora assalariado acompanhou o raciocínio de exclusão da mesma massa populacional que já havia ficado de fora das discussões sobre posse e propriedade de terras no desenrolar da história brasileira.

\section{A Violação DE DIREITOS TRABALHistas PELA OMISSÃO DELIBERADA DO ESTADO - UMA MALQUISTA CONTRIBUIÇÃO QUE DELINEOU ASPECTOS DA MANUTENÇÃO DO TRABALHO ESCRAVO BRASILEIRO.}

A despeito das diferenças visíveis nas relações dos trabalhadores e trabalhadoras urbanas, é indiscutível que o espelho da desigualdade nas relações de trabalho mostrou um reflexo mais nítido das diferenças sociais das partes na esfera rural. Isto ocorreu por diversas razões, que iam das indistintas e imbricadas relações de promiscuidade entre a esfera pública e privada que marcam o Brasil, à mera constatação de impunidade no descumprimento das novas e incipientes determinações de proteção trabalhistas obtidas ainda extremamente simplistas. Elenca com otimismo MARQUES (2009, p.185) sobre os "ganhos" antes de 1943: "além de ter a liberdade de contratar, passou a perceber salário". O mesmo autor, admitindo porém "injustiças nas relações com a classe patronal", também observa que trabalhadores que não possuíam vínculos de emprego e sim a celebração de contratos agrários, mesmo que regulamentados no Código Civil, "penavam na mão dos mais fortes, seja na exorbitância dos alugueis cobrados (nos arrendamentos) seja na injusta partilha dos frutos (nas parceiras) em que predominavam os interesses dos proprietários".

A crítica do agrarista demonstra, todavia, uma suavidade que vislumbra pouco dos abusos ao longo deste e de outros períodos. O Estado, todavia, termina por assumir a ofensiva 
inicial aos direitos de trabalhadoras e trabalhadores rurais no advento da legislação trabalhista em 1943. O art. $7^{\circ}$ da CLT à época era seco:

Art. $7^{\circ}$ Os preceitos constantes da presente Consolidação salvo quando for em cada caso, expressamente determinado em contrário, não se aplicam : (Redação dada pelo Decreto-lei $\left.\mathrm{n}^{\circ} 8.079,11.10 .1945\right)$ a) aos empregados domésticos, assim considerados, de um modo geral, os que prestam serviços de natureza não-econômica à pessoa ou à família, no âmbito residencial destas; b) aos trabalhadores rurais, assim considerados aqueles que, exercendo funções diretamente ligadas à agricultura e à pecuária, não sejam empregados em atividades que, pelos métodos de execução dos respectivos trabalhos ou pela finalidade de suas operações, se classifiquem como industriais ou comerciais (BRASIL, 1943, p.1).

Os direitos como salário mínimo, férias anuais remuneradas, aviso prévio entre outros, ventilados por autores como MARQUES ou OPTIZ de que foram concedidos ainda que parcialmente a trabalhadoras e trabalhadores rurais (MARQUES, 2009, p.185 e OPTIZ, 2012,p.142) são pouco vislumbrados por uma breve pesquisa ainda que recente nas monoculturas brasileiras. Prevaleceram (inclusive até os dias atuais) contratos por safras que não contemplam frequentemente estes direitos mencionados.Nesse sentido, recordamos inclusive que a prática do trabalho infantil e adolescente, tolerada e mesmo incentivada nas plantações canavieiras nordestinas não apenas tem marcas recentes como abre uma discussão relevante (embora não objetificada em nossa pesquisa presente) da condição de escravidão de menores cujos pais recebiam em seu nome o esforço conjunto. DOURADO, DABAT e ARAÚJO testemunham entrevista realizada pela segunda autora com o então diretor da FETAPE, na qual o mesmo reconhece que os fiscais se acostumavam a aceitar as desculpas de empregadores e não punirem usinas e refinarias. Dizia que "os donos de engenho mandavam os meninos se esconderem no canavial quando chegava a fiscalização ou até o carro do sindicato". Outro problema testemunhado era, segundo o diretor, os chamados "empreiteiros", que serviam como intermediários pelo emprego das crianças. Assinala então sobre os "empreiteiros" ou "gatos": "nem o trabalhador mirim, nem o adulto teria vínculo com a usina, só com os gatos, que não podiam pagar nada de multas ou indenizações. Esse sistema lesou o direito de muitos"(DOURADO, DABAT e ARAÚJO, 1999, p.423).

Por outro lado, é curioso notar como as esferas que congregavam mais fortemente as pessoas que até algumas décadas atrás estavam na condição explícita de escravas são justamente aquelas que encontram-se excluídas da proteção estatal com a retirada destas classes profissionais no rol dos novos direitos. O aspecto do cuidar, das intricadas relações 
onde o controle do Estado já seria deficitário pela intimidade nas residências, e por isso mesmo também, que propiciavam vulnerabilidade às pessoas empregadas, em especial mulheres e crianças (estas últimas ainda mais expostas à situações de trabalho escravo, posto que comum a prática da troca do sustento mínimo de sobrevivência em troca de trabalho doméstico sem previsão de horário). A postura compreende uma clara demissão do Estado nesta possibilidade de interferência. Na outra ponta excluída, permaneceram trabalhadores e trabalhadoras rurais, muitas vezes também misturando relações de público e privado e frequentemente em situações de dependência alimentar e de moradia, cujas origens vão nos remeter à abolição (em menor quantidade à migração) algumas décadas antes. Reforçando a vulnerabilidade da inexistência de pouso fixo para uma população fragilizada de laços e independência de moradia e escolha de trabalho.

Com as pressões dos movimentos iniciais camponeses brasileiros, diversos projetos e propostas foram elaborados depois da Constituição de 1946, prevendo estabilidade no emprego e indenização por rescisão contratual, que culminou na criação do chamado Estatuto do Trabalhador Rural, em 1963, cuja proposta havia sido encaminhada por Getúlio Vargas há quase dez anos antes. Buscando estender os benefícios trabalhistas que a Consolidação das leis do Trabalho não havia alcançado, o estatuto, porém, na prática, atingiu pouco êxito em favorecer a população rural trabalhadora brasileira.

Uma das principais ações do Estatuto que provocou polêmica era a consideração indistinta de empregador rural, cuja Lei 5.889 de 1973 vem a discriminar, ainda também passível a críticas, pois focou-se em esclarecer questões próprias do trabalho rural, terminou por omitir a finalidade da atividade exercida. Comenta SANTOS (1993, p.29) que: "a Lei 5.889 de oito de junho de 1973, regulamentada pelo decreto a.73.626 de doze de fevereiro de 1974, veio substituir o criticado estatuto do Trabalhador Rural, definindo corretamente as figuras do empregado e do empregador, especificando as peculiaridades do trabalho rural e mandando aplicar, no mais, a Consolidação das Leis do Trabalho". Em resumo, a discussão pairou sobre o fato de que nem todo trabalhador ou trabalhadora rural seria empregado ou empregada, pois na definição no primeiro caso, poderia enquadrar-se uma situação de autonomia, e não de subordinação, o que provocaria demandas inadequadas. O empregado ou empregada rural encontra-se sob situação de dependência subordinação. Também poderiam encontrar-se pessoas em situação de parceria ou arrendamento, que não se enquadrariam como empregados ou empregadas.

Lembre-se, porém, nesse período que como bem aponta Vezzalli: 


\begin{abstract}
A luta pela terra esteve sempre presente na história do Brasil, mas foi a partir da década de 40 que ganharam força os debates que ligavam os problemas sociais do país à existência do latifúndio e a necessidade de realizar a reforma agrária para superar os conflitos no campo. Nos anos 60, floresceram as ligas camponesas no Nordeste e a organização dos trabalhadores rurais com o objetivo de reivindicar a distribuição mais equitativa da terra - o que aumentou a pressão pela realização da reforma agrária durante o governo do presidente João Goulart (VEZZALLI, 2006).
\end{abstract}

Com o golpe militar de 1964, observa-se que a noção de capital monopolista também atendeu à esta batuta na esfera da agricultura. Mesmo com a criação do Estatuto da Terra, não se vislumbrava uma reforma agrária que diminuísse a desigualdade social e sim uma intensa criação de assentamentos com o objetivo de fixar mão-de-obra barata perto de fazendas, bem como incentivos fiscais foram disseminados para a ocupação das chamadas fronteiras agrícolas, que beneficiou latifúndios como da Volkswagem e Bradesco 4 .

\title{
5 A ESCRAVIDÃo POR DÍVIDAS CONTEMPORÂNEA E SUA RELAÇÃO COM A QUESTÃO AGRÁRIA BRASILEIRA.
}

Um dos desafios atuais à erradicação do trabalho escravo atual compreende que à situação de grandes proprietários e proprietárias de terras - fortalecida pela ancestralidade dos latifúndios no Brasil- somou-se o estabelecimento de grandes empresas de agricultura e pecuária brasileiras e multinacionais. Desta forma, este combate passa por uma tarefa extremamente difícil, que é a imposição de prejuízos financeiros significativos de forma a inviabilizar os lucros ou competitividades gerados com a prática. No evento "Acabando com Formas de Escravidão Contemporânea em Cadeias Produtivas", realizado durante a 30a reunião do Conselho de Direitos Humanos das Nações Unidas, em Genebra, na Suíça, debateu-se justamente que é raro que empresas adotem espontaneamente compromissos que possibilitem que estas monitorem e atuem em suas cadeias produtivas; bem como que os governos fiscalizem a situação trabalhista e garantam a existência e aplicabilidade de legislação que envolvam o setor empresarial. Isto também inclui a discussão de padrões legais, políticas públicas e marcos legais. Ainda que o Brasil tenha uma política nacional de combate ao crime de escravidão contemporânea, criada em 1995 e mantida pelos últimos governos, o desafio se faz presente em diversos aspectos, dos quais mencionaremos em especial o aspecto da escravidão por dívida na esfera agrária brasileira e sua relação com a frágil Política Agrária brasileira.

\footnotetext{
4 A Comissão Pastoral do Trabalho recebeu as respectivas denúncias envolvendo o trabalho escravo. Mais informações $<$ http://www.cptnacional.org.br/index.php/acoes/campanhas/6-trabalho-escravo/trabalho-escravo-/195-campanha-de-prevencao-e-combate-ao-trabalho-escravo17 $>$ Acesso em março de 2016.
} 
Pouco antes da Constituição brasileira, após décadas de pressão da sociedade civil, que desde 1970 denunciava a ocorrência de trabalho escravo contemporâneo, o governo brasileiro reconheceu em 1995 diante das Nações Unidas a existência dessa exploração, estabelecendo política pública contra essa violação de direitos humanos, com grupos de inspeção do trabalho que investigam denúncias, libertam trabalhadoras e trabalhadores, obrigam o pagamento de salários e direitos trabalhistas e dão início a processos para compensação das vítimas ou punição criminal de responsáveis. Somou-se a isto um cadastro nacional a partir de 2003, realizado após direito à defesa administrativa em duas instâncias, permanecendo na mesma lista por dois anos até quitar débitos e garantir que não haveria reincidência, conforme aponta Sakamoto (SAKAMOTO, 2003). Através do Pacto Nacional para Erradicação do Trabalho Escravo, esta base de dados foi utilizada por companhias públicas e privadas para sanções comerciais. Todavia, em dezembro de 2014, o Supremo Tribunal Federal concedeu uma liminar a uma associação de empresas de construção suspendendo a lista, até então não reestabelecida sua divulgação pela Advocacia Geral da União.

Esse cenário assume proporções mais profundas quando se cruzam, por sua vez, com locais de disputas de terras rurais no Brasil. Com propriedade, comentam GONZALES e ANDRADE (2007, p.59) que antes, no período colonial, era mais caro comprar e manter a propriedade de um escravo ou escrava. "Hoje pode-se dizer que o custo é zero. Pois paga-se apenas o transporte, e a dívida que o sujeito tinha em algum comércio ou hotel. Como, aos olhos dos grandes proprietários de terras, essas pessoas são 'descartáveis', se o trabalhador fica doente, é só largá-lo na estrada mais próxima e aliciar outra pessoa" Os autores então arrematam, com razão que a facilidade se dá, também, em função de fato conhecido: "o desemprego é gigantesco no país e a mão de obra, farta" (GONZALES e ANDRADE, 2007, p. 66). Embora não haja estatística oficial no Brasil, a Comissão Pastoral da Terra, entidade ligada à defesa da situação de inúmeras famílias rurais há várias décadas em terras brasileiras, possui diversos dados. É dela a primeira denúncia dentro do conceito contemporâneo de trabalho escravo no Brasil, realizada por D. Pedro Casaldáliga em 1972, dentro do conceito da escravidão por dívidas impagáveis. A Comissão, em seu documento "De olho aberto para não virar escravo" observa que:

No Brasil, existem dados de trabalho forçado com os soldados da borracha (trabalho obrigatório), onde muita gente morreu - mais de 40 mil -promovido também pelo governo. Nas décadas de 70-80, tem-se noticias de trabalho forcado em fazendas na Amazônia. Em 73, quando o governo militar fornece subsídios a grandes empresas da Amazônia, e estimado em 100 mil o 
numero de trabalhadores escravizados, por ano, ate a década de 80. Em 77, vem de Conceição do Araguaia a 1a. notícia de trabalho escravo em fazendas, dada pelos próprios trabalhadores fugitivos dessa situação. Em 74, teria havido na fazenda Bradesco - sul do Pará, a queima de 60 peões. Os trabalhadores contratados fora do estado eram levados de avião para tornar a fuga mais difícil. Normalmente, a contratação e o aliciamento se dão no Piauí, Rio Grande do Sul, Paraná, Maranhão, Espírito Santo, e os trabalhadores só se dão conta da situação de divida de viagem, cantina, ferramentas, quando chegam ao local (CPT, 2010, p. 1)

Na esfera rural, a Comissão observa que o sistema obedece a uma repetida lógica:

\begin{abstract}
Aliciamento em região distante, pagamento antecipado dos gastos do peão (pensão, feira, transporte), transporte em condições péssimas, cadeia de intermediários desde o dono da pensão até os distintos gatos, condições de trabalho precárias e perigosas, coação por meios violentos, ameaças e cerceamento da liberdade, prática do endividamento reforçado pelo sistema da compra no barracão da fazenda ou da frente de trabalho. As empreitas mais habituais, nas regiões de fronteira agrícola são o desmatamento, a derrubada para abertura de fazenda ou pastos novos, a limpeza de juquira ou juquirão, além de obras específicas (ex.: linhão da Eletronorte a partir de Tucurui-PA). No interior dos Estados, embora muitas vezes no limite entre escravidão e trabalho super-explorado, há repetidos casos em carvoarias e serrarias (MA, MG, MS, MT) (CTP, 2010, p.1).
\end{abstract}

Nesse sentido ganha eco a crítica de Manuel Correia Andrade: analisa que o escravo se viu liberto mas sem terras para cultivar, sem assistência ou ajuda, e sentiu que a liberdade então adquirida se constituía apenas no direito de trocar de senhor (ANDRADE,1980, p.92).

\title{
6 PECULIARIDADES DA ESCRAVIDÃO CONTEMPORÂNEA NA ESFERA AGRÁRIA
}

A escravidão por dívidas no trabalho agrário assume uma forma perversa que requer do Direito Agrário uma análise mais apurada pois possui pontos divergentes da escravidão urbana, mesmo que por dívidas. Ainda que a pouca capilaridade o Estado se faça através de uma redução visível de forças punitivas e fiscalizatórias, que permite o recrudescimento da violência indiscutível no campo, com inúmeros casos de tortura, assassinato e perseguição não apenas de trabalhadores e trabalhadoras (mas lideranças sindicais, ativistas ambientais e integrantes de movimentos sociais); a vigilância armada nem sempre é a primeira tática: a dívida considerada impagável, por si mesma, ganha um pesado reforço na esfera rural: o isolamento geográfico e a facilidade de "encarceramento verde" nos próprios cinturões de produção agrícola. "Em 2006 foram 6.953 em 16 Estados, com 3.633 pessoas resgatadas. Em 2007, 8.653 trabalhadores em 18 Estados, com o resgate efetivo de 5.974. Entre 1995 e 2007, 
foram oficialmente encontrados, em todo o Brasil, 30.036 trabalhadores em condição análoga à de escravos"

... forma de trabalho forçado mais encontrada no país é a da servidão ou 'peonagem', Por dívida. Nela, a pessoa empenha sua própria capacidade de trabalho ou a de pessoas sob sua responsabilidade (esposa, filhos, pais) para saldar uma conta. E isso acontece sem que o valor do serviço executado seja aplicado no abatimento da conta de forma razoável ou que a natureza ou que a natureza e a duração do serviço estejam claramente definidas (GONZALES; ANDRADE, p. 66, 2007)

Outro ponto difícil de ignorar é o cruzamento visível de dados que nos proporciona analisar que frequentemente tais proprietários e proprietárias de terras que incidem em situações de exploração humana escrava possuem ligações familiares e cruzadas com instâncias do governo executivo e tribunais brasileiros, dificultando as aplicações punitivas.

A concentração de terras, portanto, não é um dado dentro da temática do trabalho escravo rural brasileiro, mas sim uma premissa fortemente enredada em sua própria existência e razão de ser. Fabiana Vezzalli (2006 especial latifúndio) observa que:

Na raiz da desigualdade social está a concentração de terras rurais nas mãos de poucas famílias ou empresas. Cerca de $3 \%$ do total das propriedades rurais do país são latifúndios, ou seja, tem mais de mil hectares e ocupam $56,7 \%$ das terras agriculturáveis - de acordo com o Atlas Fundiário do Instituto Nacional de Colonização e Reforma Agrária (Incra). Em outras palavras, a área ocupada pelos estados de São Paulo e Paraná juntos está nas mãos dos 300 maiores proprietários rurais, enquanto 4,8 milhões de famílias estão à espera de chão para plantar (VEZZALI, 2009).

Frequentemente, as faixas de terra que hoje atendem pela concentração de agronegócio justificam sua existência no discurso de que lideram as exportações brasileiras, ainda que, analisando as funções precípuas no cerne da produtividade agrária, as propriedades pequenas médias sejam efetivamente responsáveis pela alimentação interna. Citando o próprio INCRA e a FAO, Vezzalli (2009) anota que "as pequenas propriedades representam 85,5\% dos estabelecimentos do campo, apesar de ocuparem 30,5\% das terras agriculturáveis". E destaca que "entre os dez principais produtos da agricultura familiar estão: leite, milho, feijão, café, mandioca e até mesmo a soja. Ou seja, a base alimentar do país” (VEZZALLI, 2009).

Um ponto, portanto, indiscutível para análise da questão encontra-se que: primeiro, é nas extensas faixas de terra e grandes propriedades que vem sendo encontradas as maiores quantidades de situações de trabalho escravos contemporâneos no Brasil; relacionando a

\footnotetext{
${ }^{5}$ Dados disponíveis em Escola do Governo. Mais informações em $<<$ http://www.escoladegoverno.org.br/artigos/111-politica-agraria-brasil > >. Acesso em março de 2016.
} 
concentração de terras com o fomento de situações violadoras de direitos humanos com o fito de ampliar o lucro em explorações em larga escala. Some-se à isso o segundo fato, a grilagem de terra, que propicia que a existência destas extensões cumpra duas funções: aumente-se o tamanho geográfico das terras para especulação, improdutiva, pouco produtivas ou que produzem lucro à base de trabalho escravo; ao mesmo tempo que, expulsando pequenos e pequenas posseiras de suas regiões, alimenta a engrenagem de fornecer mais mão de obra escrava para aquela e outras regiões. Acresce Vezzalli que:

$\mathrm{Na}$ sanha por adquirir mais terras, falsificam-se documentos de propriedade (prática conhecida pelo nome de grilagem) e expulsam-se antigos moradores. Há terra que foi cercada sem que os proprietários tivessem documentos para provar que poderiam cercá-la. São quase 170 milhões de hectares de terras devolutas (públicas) cercadas. O dia que o governo federal cumprir a lei do novo cadastro fundiário e fizer a medição por georreferenciamento, vai saltar aos olhos o excesso de terra pública grilada. Hoje, no Brasil, nenhum órgão público é capaz de dizer quem é proprietário do quê. Mesmo o Incra tem grandes dificuldades para analisar as cadeias dominiais das fazendas (VEZZALLI, 2006).

E este georreferenciamento deficiente, que vem nos mostrando prejuízos vários, inclusive na área ambiental, uma vez que mesmo com legislações recentes como o CAR por exemplo, estabelece certo grau de preservação ambiental que, contudo, não vislumbra a formação de corredores verdes que mantenham a sustentabilidade ambiental destes locais, entre vários aspectos não contemplados em novas legislações similares.

Firmando então três pontos significativos das claras relações entre o fortalecimento das temáticas candentes do Direito Agrário com a escravidão por dívidas rural no brasil, observamos ainda que a fragilidade da implantação da reforma agrária termina por reduzir ainda mais as esperanças de encerrarmos essa página na história. Demonstra Gonzales e Andrade citando o coordenador da CPT em Marabá que notadamente grande parte do problema seria resolvido com uma efetiva política de reforma agrária, acompanhada de juros baixos para o crédito rural e partilha de conhecimentos. "Mas infelizmente, o que prevalece é uma grande quantidade de desempregados, reserva de contingente para os trabalhos forçados nas regiões de fronteira agrícola" (GONZALES e ANDRADRE, 2007, p. 68).

A violência no campo também, por sua vez, alimenta este modelo ao produzir o silenciamento das denúncias de trabalho escravo na zona rural. Segundo dados apurados pela Comissão Pastoral da Terra, da Conferência Nacional dos Bispos do Brasil, em 2007 ocorreram homicídios ligados a conflitos agrários em 14 Estados da federação, seis a mais do que no ano anterior. "Análogo espraiamento territorial registrou-se quanto à expulsão de 
famílias do campo: enquanto em 2006 tais incidentes ocorreram em 10 unidades da federação, em 2007 eles foram registrados em 14 Estados $^{6 \%}$. Todas estas questões nos fazem observar que tais fatores constituem um sistema que se retroalimenta e desta forma se mantem.

\section{CONCLUSÕES POSSÍVEIS}

É indispensável identificar as fortes ligações de temáticas profundamente próprias do Direito Agrário com a questão trabalhista brasileira nas mazelas da escravidão por dívidas que a fragilidade de uma ampliação de debates em temáticas como Política Agrária, por exemplo, resulta em anomalias como que, mesmo havendo a denúncia de situações de trabalho escravo - que por si só é tão grave e difícil de ser levada à termo nas esferas investigativas e judiciais, conforme denúncia a $\mathrm{CPT}^{7}$ - a desapropriação de áreas por situação de trabalho escravo pode proporcionar por fim verdadeiro prêmio a proprietários e proprietárias que violam os direitos humanos.

Isto porque ainda que exista o projeto de lei do Plano Nacional de Erradicação do trabalho escravo que prevê a expropriação da propriedade de terras com constatação de trabalho escravo, esta proposta legislativa vem esbarrando em pressões da chamada bancada ruralista brasileira, conforme denuncia a Comissão Pastoral da Terra e autores como Gonzales e Andrade. O próprio Plano de Erradicação de Trabalho escravo no Brasil admite a existência provável de cerca de vinte e cinco mil pessoas vivendo em condições análogas à de escravas.

Exemplo relevante desta situação é trazida pela CPT ao esclarecer que

Apesar dos debates da sociedade organizada, tais como os realizados no Fórum Nacional contra a Violência no Campo e contra o Trabalho Escravo, são de primeira importância neste combate. Em 09/09/97, por exemplo, foi o Fórum quem pressionou o presidente do INCRA, Dr Milton Seligman, para desapropriar a fazenda Flor da Mata, no Sul do Pará (por motivo de trabalho

\footnotetext{
${ }^{6}$ Consulta de maiores informações em Escola de Governo, artigo intitulado "Os Direitos Humanos na Declaração Universal de 1948 e na Constituição Brasileira em Vigor". Disponível em $\langle$ http://www.escoladegoverno.org.br/artigos/115-direitos-humanos-declaracao-1948>. Acesso em março de 2016.

${ }^{7}$ No acompanhamento às pendências penais, os processos criminais por trabalho escravo (art. $149 \mathrm{CP}$ ) são muitas vezes arquivados antes de chegarem ao julgamento e, às vezes, antes mesmo da denúncia ou da pronúncia, por razão de prescrição. Em 22/08/97 a Justiça Federal de Marabá comunicou a relação de 11 processos criminais ligados à prática do trabalho escravo (período de 80 a 92). Desse número só 3 processos estavam ainda em andamento sendo os demais arquivados ou até sem notícia. Tudo indica que os demais nunca chegarão ao julgamento por não se encontrar mais, depois de tanto tempo, nem as testemunhas nem os acusados, que são foragidos ou com pena prescrita. Por morosidade ou má vontade da Polícia Federal, inquéritos demoram anos antes de serem concluídos (CTP, 2010, p.1)
} 
escravo). Apesar de fortes reações por parte dos políticos (grupo do governador Siqueira Campos, Estado do Tocantins) ligados à empresa tocantinense Umuarama, dona da fazenda, os quais foram até o Ministro para tentar descaracterizar o trabalho do Grupo Móvel, da PF e da CPT-Xingu, a desapropriação ocorreu e foi implantado um projeto de assentamento de 400 famílias removidas da reserva indígena vizinha dos Kaiapó-Xicrín. Foi muito questionado e denunciado o fato que o proprietário da fazenda Flor da Mata recebeu do governo federal uma indenização de $\mathrm{R} \$ 2.500 .000$, enquanto ele tinha comprado a fazenda, 3 anos antes, pelo valor de R\$ 100.000 (CTP, 2010).

Tal situação demonstra, inclusive, que o trabalho escravo nas esferas rurais ainda pode estar relacionado a um quarto fator praticamente alheio aos debates relativos ao Direito Agrário em si. Que mesmo o combate pode terminar, enquanto permanecer nos moldes atuais, por instrumentalizar uma nova modalidade de lucro ao latifúndio, improdutividade e violação de direitos (e por isso a urgência de uma forte ampliação dos debates no Direito Agrário brasileiro, que contemple claramente questões conhecidas, como Reforma e Política Agrária, mas que também contemple profundamente suas interrelações como trabalho rural e as relações diversas na esfera rural).

É indiscutível que a realidade agrária brasileira tem profundas feridas ainda abertas e seculares. $\mathrm{O}$ apossamento de terras públicas devolutas, a participação de membros e membras de tradicionais oligarquias que remontam ao descobrimento e migrações estrangeiras nas grandes guerras mundiais e durante o período militar brasileiro com a abertura de capital estrangeiro, a titulação irregular do solo, grilagem e mesmo a vergonhosa e atrasada situação cartorária hereditária brasileira, que caminha a passos de formiga para moralização em nosso país, atuam como forças enraizadas negativas no cenário agrário hodierno. Soma-se à essa situação a ocupação de terras indígenas, reeditando massacres ao estilo Paralelo Onze com novas roupagens, mas ainda perversas, como a percepção de que reservas indígenas fossem meros parques antropológicos e não justos direitos penosamente obtidos. A violência da paralisação da efetivação dos direitos quilombolas previstos na Carta de 88 ainda em xeque sob inúmeros aspectos, e fomentando crimes diversos acobertados em instâncias estatais. O aumento visível de violência no campo, eliminação sumária de lideranças em diversas áreas em conflito com interesses econômicos não enfrentados pelo governo local e mesmo o governo federal brasileiro nos demonstram, claramente, que o problema das distorções que fomentam o trabalho escravo rural passa muito além dos desvios que fomentam violações trabalhistas comuns.

O trabalho escravo rural, notadamente a escravidão por dívidas brasileira na esfera rural, encontra-se profundamente ligada, alimentada e estruturada em questões tipicamente 
debatidas pelo Direito Agrário no Brasil. Cujas forças ainda não encontraram somatório adequado para ampliar vozes em favor da erradicação destas violações que mancham a terra e as relações humanas no campo. Nossa resposta, portanto, compreende contribuir com o debate dentro do Direito Agrário, fortalecendo a discussão da temática não apenas para além do Direito do Trabalho, mas contribuindo intelectualmente para alimentar progressos ao Programa de Erradicação do Trabalho Escravo no Brasil, com a atualização do debate agrário com foco nas pessoas e nas relações no campo e a unidade destas relações com uma legislação responsiva e atualizada.

Discutir as pontas menos visibilizadas destas distorções, dentro do Direito Agrário, é, portanto, indispensável para construir um Direito Agrário que vislumbre a preservação dos direitos humanos, consoante perspectivas constitucionais, ambiental, sobretudo de justiça e paz.

\section{REFERÊNCIAS BIBLIOGRÁFICAS}

ANDRADE, Manuel Correia. A Terra e os Homens do Nordeste. São Paulo: Ciências Humanas, 1980.

BRASIL. Consolidação das Leis do Trabalho, 1943. Disponível em $<$ http://www.planalto.gov.br/ccivil_03/decreto-lei/Del5452.htm\#art7>. Acesso em março de 2016.

CARDOSO, Cyro Flamarion. Escravo ou camponês? O proto-campesinato negro nas Américas. São Paulo: Brasiliense, 1987.

CARVALHO, José Murilo. Teatro de sombras: a política imperial. Rio de Janeiro: IUPERJ, 1980.

CTP, Comissão Pastoral da Terra. De olho aberto para não virar escravo. In Campanha de Prevenção e Combate ao Trabalho Escravo. 2010. Disponível em $<$ http://www.cptnacional.org.br/index.php/component/content/article?id=195:campanha-deprevencao-e-combate-ao-trabalho-escravo>. Acesso em março de 2016.

DOURADO, DABAT, ARAUJO, Ana, Christine e Teresa Correa. Crianças e Adolescentes nos Canaviais de Pernambuco, in História das Crianças no Brasil,organização de Mary Del Priori,São Paulo: Contexto, 1999.

ESCOLA DO GOVERNO. A política Agrária no Brasil. São Paulo. 2008. Disponível em $<$ http://www.escoladegoverno.org.br/artigos/111-politica-agraria-brasil $>$. Acesso em março de 
GONZALEZ, Everaldo Tadeu Quilici; ANDRADE, Maurício. A questão da Terra e o Trabalho Escravo no Brasil: Violação do princípio da dignidade da pessoa humana. In Cadernos de Direito. Piracicaba, pp. 59-69, jan/dez 2007.

GULLAR, Ferreira. Toda poesia. Rio de Janeiro: José Olympio, 2004.

LARANJEIRA, Raymundo. Direito Agrário.São Paulo:LTR,1984.

MARQUES, Benedito Ferreira. Direito Agrário Brasileiro. São Paulo: Atlas, 2009.

SAKAMOTO, Leandro. Dossiê Trabalho Escravo. Agência Carta Maior, São Paulo, 2003. Disponível: $<$ http://agenciacartamaior.uol.com.br/agencia.asp? coluna=reportagens\&id=1157 $>$. Acesso em março de 2016.

OPITZ, Silvia C. B. OPITZ, Oswaldo. Curso Completo de Direito Agrário. São Paulo: Editora Saraiva, 2012.

SANTOS, Saulo Emídio. Trabalhador rural: relações de emprego. Goiânia: AB,1993.

VEZZALI, Fabiana. Concentração de terra na mão de poucos custa caro no Brasil. Geografia é Luta- Prof. Mazucheli, 2006. Disponível em <http://profcmazucheli.blogspot.com.br/2009/08/concentracao-de-terra-na-mao-depoucos.html>. Acesso em março de 2016. 